\title{
A Novel Electrothermally Actuated RF MEMS Switch for Wireless Applications
}

\author{
Jitendra Pal, Yong Zhu, Sr. Member IEEE, Junwei. LU, Sr. Member IEEE, Dzung Viet Dao \\ Queensland Micro and Nanotechnology \\ Griffith University \\ Gold Coast, Australia \\ Email: jitendra.pal@griffithuni.edu.au,y.zhu@griffith.edu.au, \\ j.lu@griffith.edu.au, d.dao@,griffith.edu.au
}

\begin{abstract}
This paper presents a new type of thermally actuated switch for wireless communication system operated at low gigahertz frequencies. The switch is driven by a metal electrothermal actuator, which can generate large displacement and high contact force at lower temperatures. The MEMS switch utilizing the parallel four-beam actuator requires driving voltage of $0.07 \mathrm{~V}$ for an $8 \mu \mathrm{m}$ displacement. RF performances are improved by suspending the structure $25 \mu \mathrm{m}$ from the substrate using MetalMumps process. An ON state insertion loss of $\mathbf{- 0 . 2 7} \mathrm{dB}$ at $10 \mathrm{GHz}$ and an OFF state isolation of $-40 \mathrm{~dB}$ at $10 \mathrm{GHz}$ are achieved on low resistivity silicon substrate.
\end{abstract}

Keywords - Electrothermal actuator, low resistivity substrate, RF MEMS switch, low driving voltage, MetalMumps

\section{INTRODUCTION}

Wireless communication technology is rapidly growing around the world and this trend is likely to continue for the growth of emerging consumer, microwave and millimetre wave circuits and systems also. However, some off-chip bulky passive element such as varactor or PIN diodes, inductors, quartz crystals, and SAW filters, have become limiting for the chip scaling down [1]. Hence, RF MEMS featuring small size, low weight and high performance can be considered a future enabling technology to replace these off-chip passive elements [2].

In previous work, PIN diodes were used for the RF switching of an antenna arrays for the purpose of beam steering. However, PIN diodes have lower Q at high frequencies and therefore high insertion loss. Compared with the PIN diodes, MEMS switches offer higher Q at high frequencies, low insertion loss, higher isolation and smaller packaging size. Also the idea of System on Chip (SOC) becomes more realistic on the communication system due to compatibility of MEMS switch with the IC process. Hence, the integration of MEMS switches into RF subsystems is expected to provide benefits.
In the past, various actuation approaches have been demonstrated utilizing various operation principles such as electrothermal actuation, the electrostatic actuation, the piezoelectric actuation, and the electromagnetic actuation. Among all of these processes, electrostatic and electrothermal actuators are most attractive. The electrostatic actuators offers low power dissipation and high driving frequency, but suffers from less functional robustness, high actuation voltage and small range of controllable displacement. In contrast, the electrothermal actuators have capability in generating relatively large actuation displacement and force, but a relatively high power consumption as compared with the electrostatic actuators. Therefore, the actuation method should be selected according to the application requirements of the switches [3].

Here, we propose a thermally actuated RF latching switch that is used to replace PIN Diodes, which were used for switching the beam of a patch antenna with thirteen hexagonal element (PATHE) array operating at frequency range of 2.4 -5.8 GHz as illustrate in Fig 1.

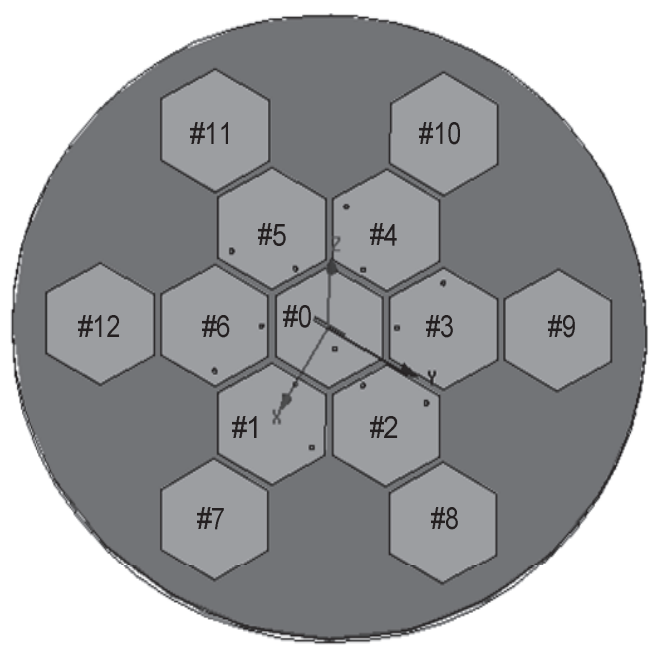

(a) Layout of patch antenna with thirteen hexagonal elements 


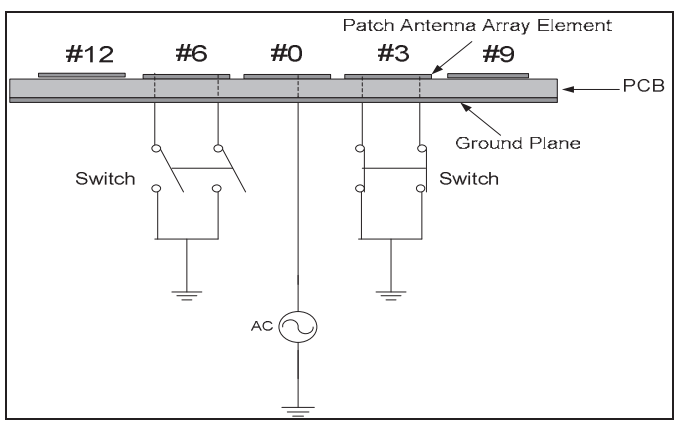

(b) Dual-switch circuit for beam forming

Fig. 1. Layout and A typical beam-forming circuit for the single-feed circularly polarized patch antenna array

The proposed RF MEMS switch is optimized by using MetalMumps process [4], a commercially available Multiproject Project Wafer (MPW) service. Through MetalMumps process the substrate loss (a trench $25-\mu \mathrm{m}$ deep is carved under the device, resulting in a suspended switch) can be reduced substantially. Also, it can provide a good solution for the integration of MEMS with IC. Hence, bring the concept of System on chip (SOC) into reality.

\section{DESIGN OF RF MEMS SWITCH}

\section{A. Operational Principle}

Fig 2 shows the operational principle of thermally actuated MEMS switch. A V-shaped actuator, which is made of precurved nickel beams, is employed to provide lateral motion in the wafer plane. This switch adopted a piece of silicon nitride as an isolation layer between the driving structure and contact structure. When voltage is applied on the beam, an electrothermal actuator generates movement due to expansion of its material and allows contact heads to move forward and connect to RF signal lines to turn on the switch,

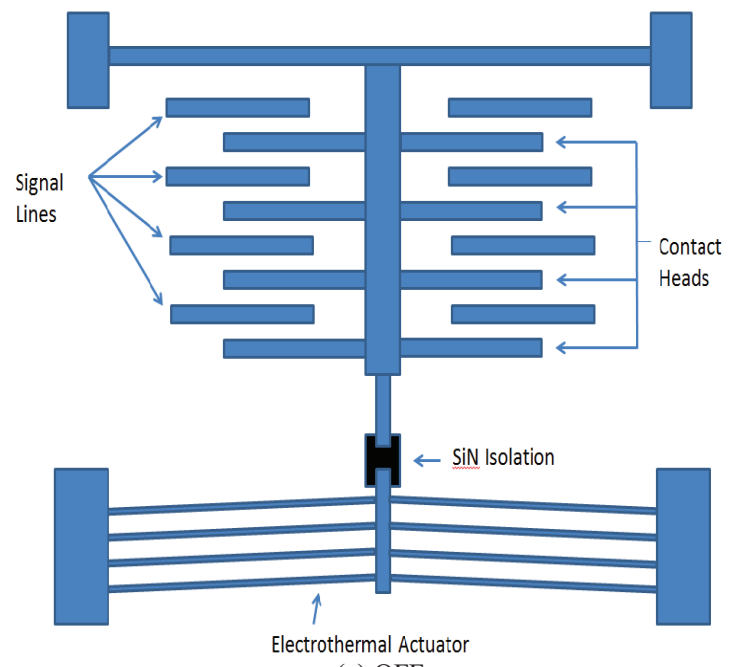

(a) OFF

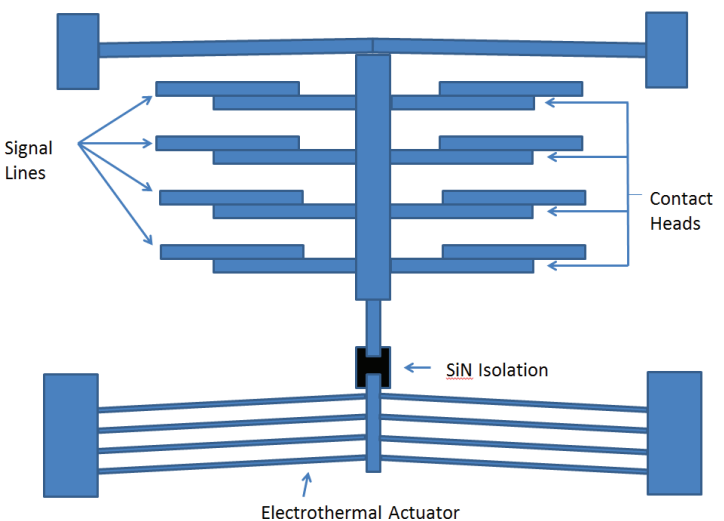

(b) ON

Fig. 2. Working principle of thermally actuated MEMS dual switch

as illustrated in Fig 2(b). On removing the driving voltage, the switch returns back to its original position due to internal restoring force of the beam, as illustrated in Fig 2(a).

\section{B. Actuator Design}

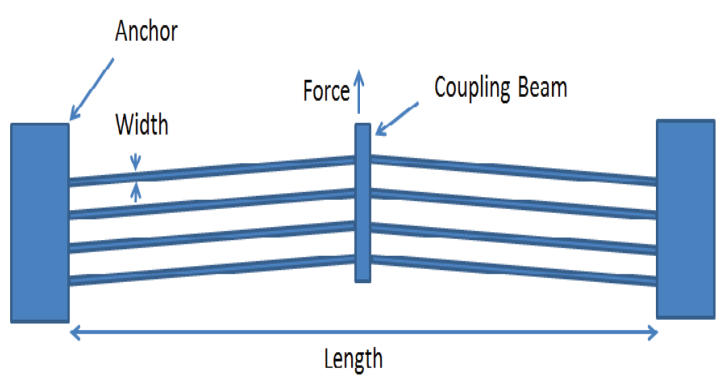

Fig. 3. Schematic diagram of the $\mathrm{V}$ shape parallel beams thermal driven structure

Thermal actuators are very good candidates for RF MEMS switch as it offers high contact force and low contact resistance with a low actuation voltage. In this work, $\mathrm{V}$-shaped electrothermal actuator beams are chosen for their rectilinear displacement caused by joule heating and their design and flexibilities. The beam is normally designed with careful considerations such that temperature is below $450^{\circ} \mathrm{C}$ to prevent plastic deformation and surface oxidation [5], higher force is generated to allow better contacts and lower metallic losses, which translate in lower switch insertion loss. Therefore, following equations were kept in mind, while designing structure [6].

$$
\begin{gathered}
d=\left[l^{2}+2(l) l^{\prime}-l \cos (\theta)\right]^{1 / 2}-l \sin (\theta) \\
F=N \frac{E w^{3} t}{4 l^{3}} d
\end{gathered}
$$

Where

$$
\begin{aligned}
& \mathrm{d}=\text { actuator displacement } \\
& \mathrm{l}=\text { length of the beam } \\
& \mathrm{l}^{\prime}=\text { elongation of the beam due to thermal }
\end{aligned}
$$




$$
\begin{aligned}
& \quad \theta=\text { prebend angle of the beam } \\
& \mathrm{F}=\text { applied force } \\
& \mathrm{N}=\text { Number of actuators } \\
& \mathrm{E}=\text { Young Modulus } \\
& \mathrm{t}=\text { beam thickness } \\
& \mathrm{W}=\text { beam width }
\end{aligned}
$$

The Fig 3 illustrates V shaped actuators in our switch. Clearly, device performances can be improved by changing the structure of the beam. Practically, at a given temperature beam displacement can be increased by increasing the beam length or reducing the bending angle. The actuators exhibit an output force which is directly affected by the thickness and width of the beam [6].

TABLE 1

Properties of Polysilicon and Nickel

\begin{tabular}{|l|l|l|l|l|l|}
\hline Material & $\alpha(\mathrm{ppm} / \mathrm{k})$ & $\begin{array}{l}\rho \\
(\Omega \mathrm{m})\end{array}$ & $\begin{array}{c}\mathrm{K} \\
(\mathrm{W} / \mathrm{mK})\end{array}$ & $\begin{array}{c}\mathrm{E} \\
(\mathrm{Gpa})\end{array}$ & $\mathrm{Q}$ \\
\hline Polysilicon & 2.5 & $\begin{array}{l}3.1 \mathrm{x} \\
10^{-5}\end{array}$ & 65 & 165 & $\begin{array}{l}2.33 \mathrm{x} 1 \\
0^{-13}\end{array}$ \\
\hline Nickel & 12 & $8 \times 10^{-8}$ & 91 & 210 & $\begin{array}{l}6.28 \mathrm{x} 1 \\
0^{-13}\end{array}$ \\
\hline
\end{tabular}

Nickel is chosen for the actuator building material as figure of merit of nickel $Q=\alpha / k E$, where $\alpha$ is the thermal expansion coefficient, $\mathrm{k}$ is the thermal conductivity, and $\mathrm{E}$ is the Young modulus, is better than polysilicon. Also, thermal expansion coefficient of nickel (see small inset in Table 1) is high compare with polysilicon, therefore exhibit same displacement at a lower temperature [7-8].

The area of proposed microswitch is approximately 1000 $\mu \mathrm{m} \times 470 \mu \mathrm{m}$. Dimension of a single $\mathrm{V}$ beam actuator is $1000 \mu \mathrm{m}$ in length, $10 \mu \mathrm{m}$ width, $20 \mu \mathrm{m}$ thickness, $10 \mu \mathrm{m}$ offset at the centre, and $1.05^{\circ}$ prebending angle respectively. The RF signal lines are separated from the contact head by 8 $\mu \mathrm{m}$ and contact area is designed to be $70 \mu \mathrm{m}$ X $20 \mu \mathrm{m}$.

\section{FABRICATION}

The device is optimized on a low resistivity substrate (1-2 $\Omega$-cm) using MetalMumps technology, a recent commercially available multi project wafer process and simulated in virtual clean room simulation module (Visualize in Fabviewer) in Intellisuite software. The design process includes a $2 \mu \mathrm{m}$ thick isolation layer on starting silicon wafer [Fig 4 (a)]. This is followed by the deposition

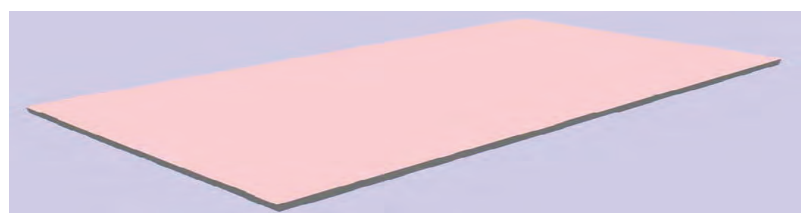

(a)

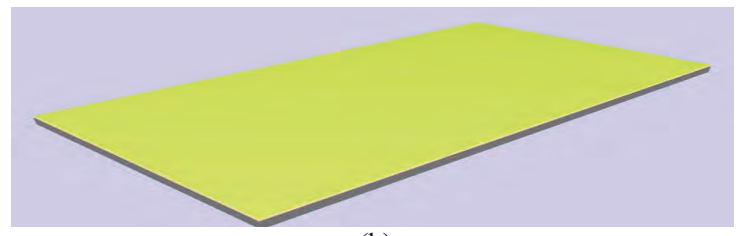

(b)

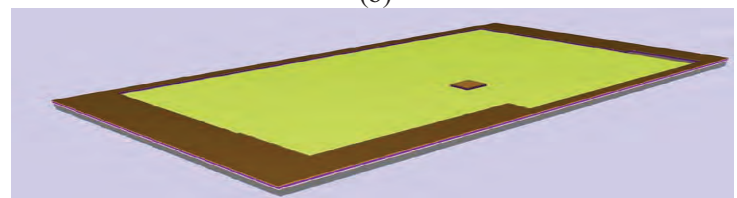

(c)

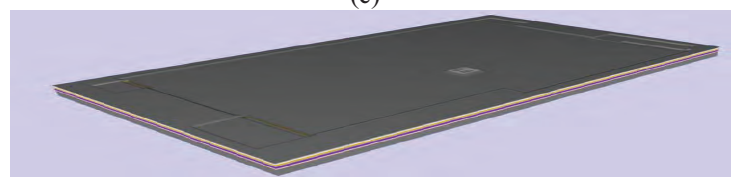

(d)

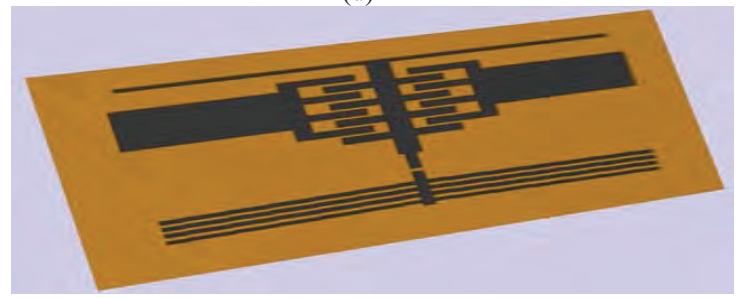

(e)

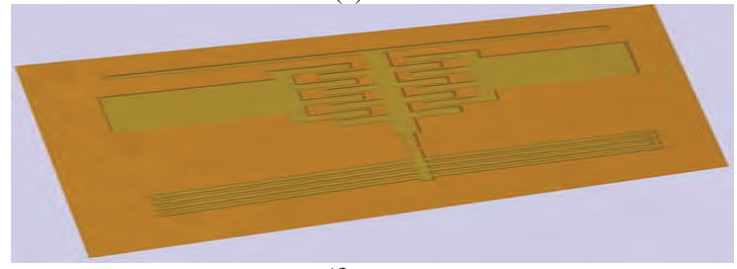

(f)

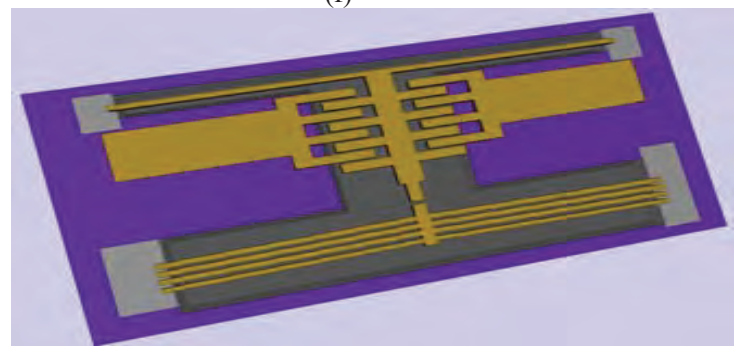

(g)

Fig. 4. Process flow for the fabrication of RF MEMS switch using MetalMumps

of a $0.5 \mu \mathrm{m}$ thick sacrificial layer (oxide 1) defining the area where the trench under the device will be patterned at the end of the process [see Fig 4 (b)]. Afterwards, two sequential silicon-nitride layers (nitride $1+$ nitride 2 ) are deposited and patterned [see Fig 4 (c)] forming structural connection as well as electrical and thermal isolations between actuator and RF signal lines. Then, access pads are defined in a second sacrificial layer [see Fig 4 (d)]. The wafer is patterned with $20 \mu \mathrm{m}$ thick structural nickel layer into the patterned resist stencil [see Fig 4 (e)]. After electroplating, gold layer is electroplated [see Fig 4 (f)]. Finally, $\mathrm{KOH}$ solution is used to form a $25 \mu \mathrm{m}$ deep trench in the silicon substrate [see Fig 4 (g)]. 


\section{IV. $\quad$ SIMULATION RESULTS}

The structure was simulated using Intellisuite software. The ends of the beams were fixed and the boundary was set at the temperature of $25^{\circ} \mathrm{C}$ at the end of the beams. When voltage is applied at the end of the beams, current flow through the beams and generates heat. Hence, actuators generate movement due to expansion of its material. Fig 5 and Fig 6 shows the measured static displacement and maximum temperature as a function of driving voltage for an electroplated Ni parallel four-beam actuator. It indicates that the displacement and temperature increased with the driving voltage as expected. For an $8 \mu \mathrm{m}$ maximum displacement a dc bias voltage of $0.07 \mathrm{~V}$ and $55^{\circ} \mathrm{C}$ maximum temperature (In Fig 6 the circle shows the point at which the contact occurs) are required.

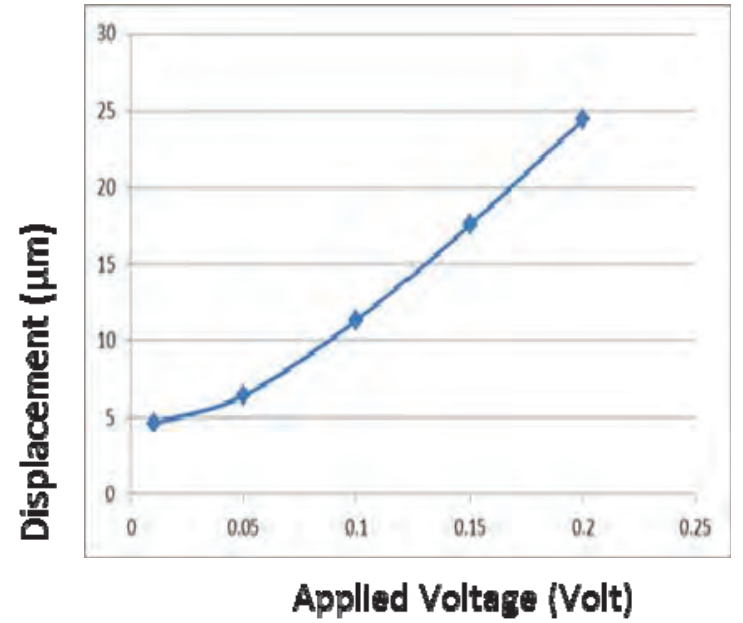

Fig. 5. Simulated static displacement at the actuator as a function of applied voltage

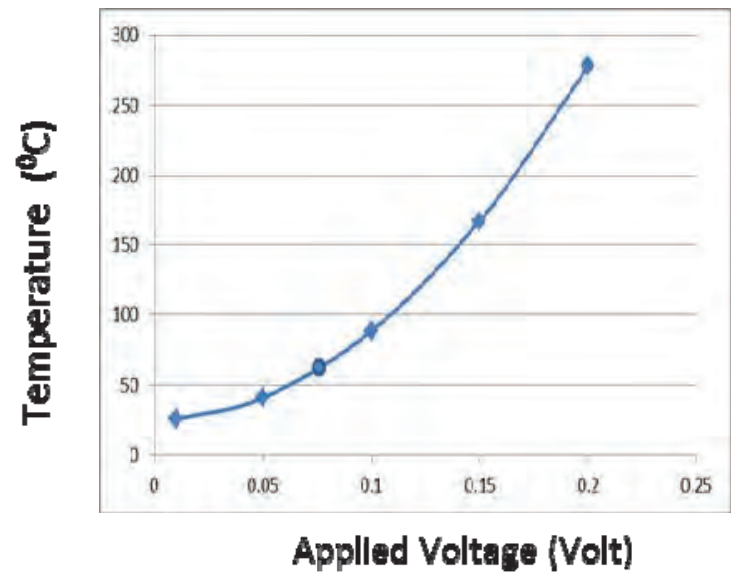

Fig. 6. Simulated maximum temperature at the actuator as a function of applied voltage

Fig 7 indicates measured contact force. Under a $0.1 \mathrm{~V}$ driving voltage, the actuator provide a contact force of approximate $3.3 \mathrm{mN}$, which is directly applied on micro switches to provide stable contacts.

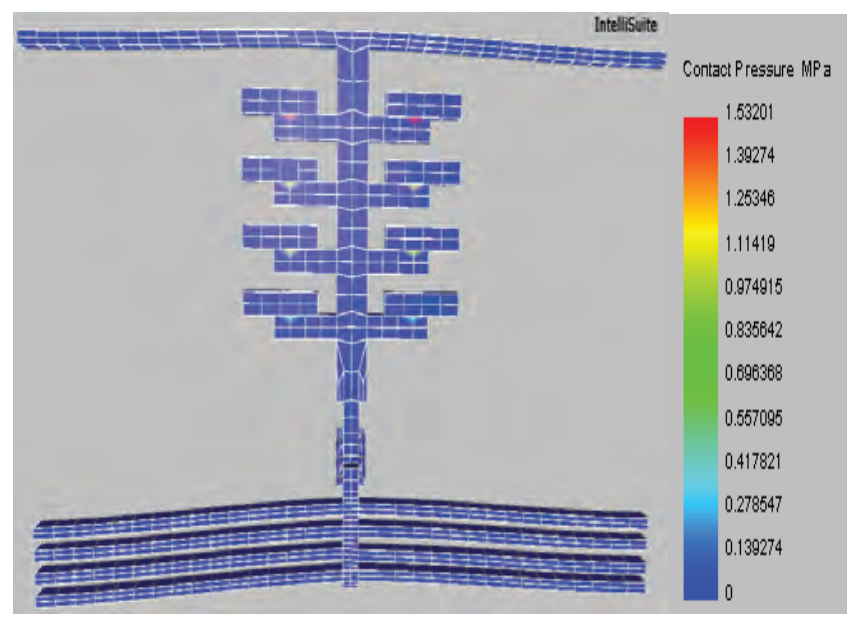

Fig 7: Simulated contact force for microswitch

Fig 8-11 illustrates $\mathrm{S}$ parameter results for the on and off state for RF MEMS switch in the frequency range of $1 \mathrm{GHz}$ to $10 \mathrm{GHz}$ using COMSOL Multiphysics. The plot shows that micro switch on the low resistivity substrate has an isolation of about $-70 \mathrm{~dB}$ at $1 \mathrm{GHz}$ and about $-40 \mathrm{~dB}$ at 10

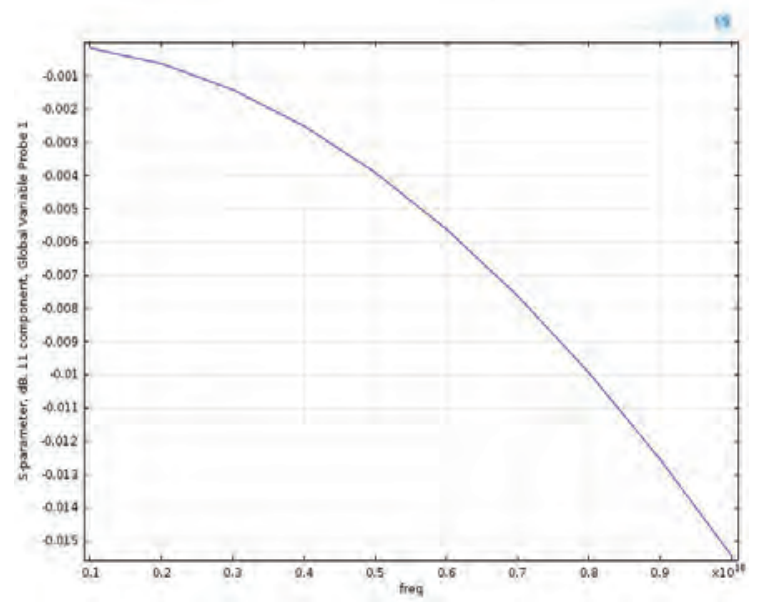

Fig. 8: OFF state return loss for MEMS switch

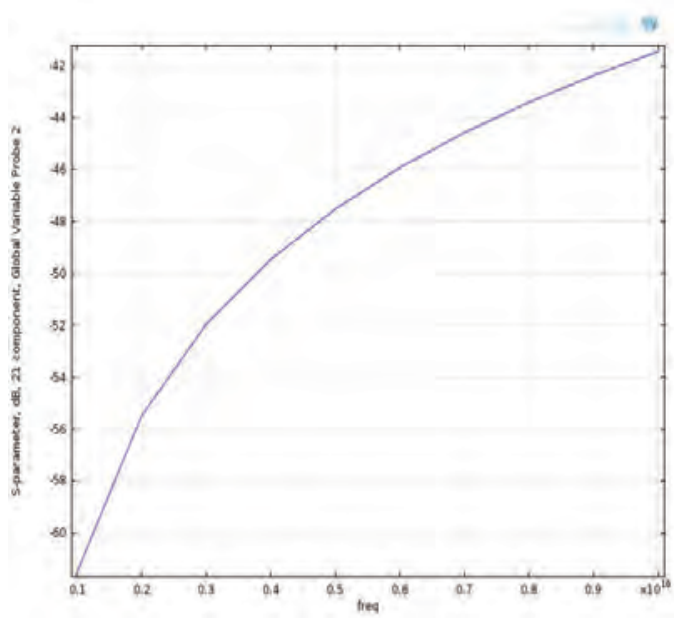

Fig. 9: OFF state isolation for MEMS switch 


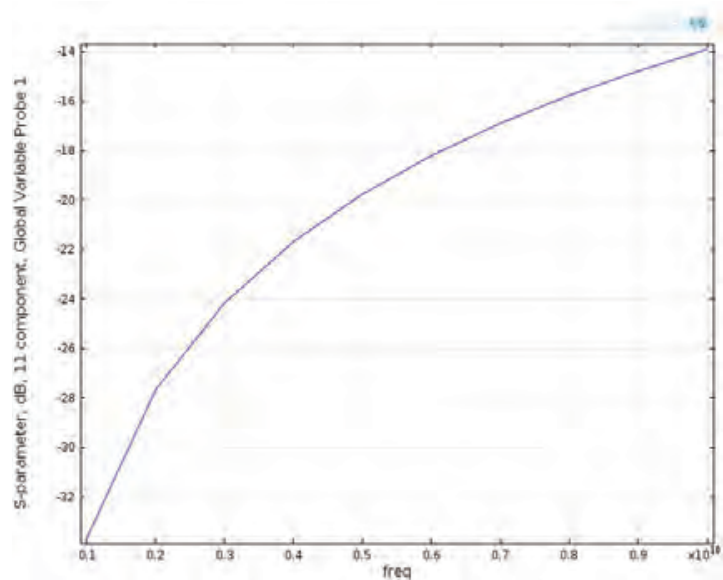

Fig. 10: ON state return loss for MEMS switch

GHz. Higher contact force provides low RF insertion loss thus insertion loss of about $-0.27 \mathrm{~dB}$ at $10 \mathrm{GHz}$ is obtained for the same switch. Also, switch shows good return loss at the frequency range of $1 \mathrm{GHz}$ to $5 \mathrm{GHz}$. The measured RF results confirm the approach to suspending the structures on a low resistivity substrate to obtain high performances of switch at low gigahertz frequencies.

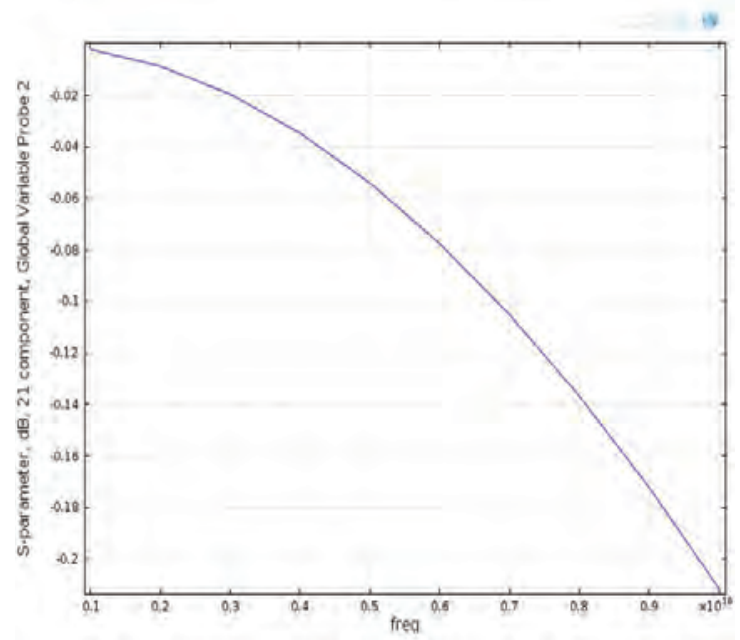

Fig. 11: ON state insertion loss for MEMS switch

\section{CONCLUSION}

An electrothermally actuated lateral contact microswitch for RF applications is designed on a low resistivity silicon substrate using MetalMumps process. Electrothermal actuation is used as the driving principle as it provides higher contact force thus lower insertion loss. Measured insertion loss and isolation are $-0.27 \mathrm{~dB}$ and $-40 \mathrm{~dB}$ at 10 $\mathrm{GHz}$ respectively. The return loss of the switch is also better than $-20 \mathrm{~dB}$ at frequency range of $1 \mathrm{GHz}$ to $5 \mathrm{GHz}$. It is verified that RF performances can be improved by suspending the switch $25 \mu \mathrm{m}$ above the substrate. This technique would possibly allow the switch to be integrated with active circuitry manufactured on a low resistivity substrate in a system on chip concept, while sustaining good $\mathrm{RF}$ performances. It is expected that the proposed MEMS switches will provide good performances compared with PIN diodes.

\section{ACKNOWLEDGMENT}

This work is supported by Griffith University, Australia under "Griffith University New Research Grant" research fund

\section{REFERENCES}

[1] H. A. C. Tilmans, W. de Raedt, and E. Beyne, "MEMS for wireless communications: 'From RF-MEMS components to RF-MEMS-SiP'," J. Micromech. Microeng., vol. 13, no. 4, pp. 139-163, Jul. 2003.

[2] D. Girbau, N. Otegi, L. Pradell, and A. Lázaro, "Study of intermodulation in RF MEMS variable capacitors," IEEE Trans. Microw. Theory Tech., vol. 54, no. 3, pp. 1120-1130, Mar. 2006.

[3] W. Shi, N.C. Tien, Member, IEEE, and Z. Li, Member, IEEE "a Highly Polysilicon as Isolation Material" Journal of Micromechanical Systems, Vol. 16, No. 5, PP. 1173-1184, Oct. 2007

[4] A. Cowen, B. Dudley,E. Hill, et al.,"MetalMUMPs Design Handbook", Rev. 1.0. http://www.memsrus.com/ncmumps.metal.html.

[5] J. K. Luo, Y. Q. Fu, J. A. Williams, Fellow, ASME, and W. I. Milne, "Thermal Degradation of Electroplated Nickel Thermal Microactuators," Journal of Microelectrothermal Systems, Vol. 18, No. 6, pp. 1279 - 1287, December 2009

[6] M.J. Sinclair, " A High Force Low Area MEMS Thermal Actuator," IEEE Inter Society Conference on Thermal Phenomena, 2000, pp. $127-132$.

[7] D. Girbau, L. Pradell, A. Lazaro and A. Nebot, " Electrothermally Actuated RF MEMS Switches Suspended on a Low- Resistivity Substrate," Jornal of Microelectrothermal Systems, Vol. 16, No. 5, pp. 1061- 1070, October 2007.

[8] Y. Zhu, A. Bazaei, S.O.R Moheimani, M.R. Yuce, “ Design , modeling , and control of a micromachined nanopositioner with integrated electrothermal actuation and sensing", Journal of Microelectromechanical Systems, Vol. 20, no. 3, pp 711-719, 2011. 